\title{
Comparison between Growing Plants in Hydroponic System and Soil Based System
}

\author{
Raneem Gashgari, Khawlah Alharbi, Khadija Mughrbil, Ajwan Jan, Abeer Glolam \\ Department of Industrial Engineering, King Abdulaziz University \\ Jeddah 21589, Saudi Arabia \\ rgashgari0001@stu.kau.edu.sa
}

\begin{abstract}
As the world population grows, the demand and need for different products, especially food products, grow as well. Because of this growing demand, there will be an expected food crisis in the coming years. To prevent that crises from happening, other methods -farming methods- and sources of food must be used. This paper studies two farming systems to compare and find the best system that will cover the current and future demand with the least cost and natural resources consumption. The first system is the soil-based system (traditional), and the other is the hydroponic system. Two types of seeds were used, cucumber and Armenian cucumber. Over a period of 30 days, the heights of the plants for both systems were measured. After collecting data, the data were analyzed using Design-Expert and the variance test (ANOVA). The hypothesis of the test is the type of seeds, planting system, and their interaction do have a significant effect on the height of the plant or not. The experiment resulted in that the type of seeds doesn't have a significant effect on the plant growth. However, the planting system has a significant effect on the plant growth, the hydroponic system has a higher growth rate. This result achieves the aim of this paper which is finding a planting system that can increase the productivity to cover the food demand.
\end{abstract}

Keywords: Hydroponic System, Soil Based System, ANOVA, Planting System.

\section{Introduction}

World population projected to reach 9.7 billion by 2050. At the same time, it has been estimated that $50 \%$ of the arable land around the world will be unusable for farming [1]. Consequently, the food production has to be increased by $110 \%$ to meet the high demand. According to United Nations Organization (UN), today many countries are facing food crisis especially in Africa. The food crisis is expected to last to 2050 if the demand will not be covered [2]. The major reason for this crisis is the climate change due to drought or floods as they became more frequent. Another reason, the poverty of many countries especially in Southern Africa, poverty reduces food output as the irrigation and fertilizers become inaccessible. The third reason is the soil erosion and degradation due to traditional farming methods that depend mainly on soil and therefore, strip the soil from its vitamins and minerals. Because of that, the world needs to develop and apply techniques to improve and increase the productivity of farming systems. Today farming systems fundamentally based on soil, water and resilience to disasters. Hence, there is a need to change and develop the economic policies of current farming systems.

\section{Problem Statement}

Nowadays, the traditional farming system does not meet the current and future demand of food. Therefore, there is a real need for adapting new farming system that stimulates plants to grow faster. This system should cover the fast-growing demand with less cost and minimum consumption of natural resources.

Hence, the main goal of the study is to find an alternative system that covers the current and future demand with less cost and minimum consumption of natural resources. There are also the following specific objectives:

- Compare and select between growing plants in hydroponic system and growing plants in a traditional soil system.

- Formulate and test a hypothesis.

- Use the statistical approach to support the hypothesis of the study.

- Provide recommendations for future work. 


\section{Literature Review}

Many studies have been conducted in developing food production techniques. One of them is the soil less farming systems. Soil less systems developments can reduce farmer's consumption of resources such aquaponics and hydroponics [1]. Aquaponics systems combine fish farming with the practice of raising plants in water in a controlled environment [2]. It is the integration of hydroponics and aquaculture. The system relies on fish's wastes to provide organic nutrients to help plants in growth. On the other hand, plants filter, clean and recycle the water back to the fish by creating a symbiotic relationship [2]. Aquaponics system consumes around 2\% of the water that traditional systems consume for the same kind of vegetable [1].

In hydroponics system, plants' roots are suspended in nutrient-rich water so they can grow without the need for any chemicals. The offers both home gardeners and commercial vegetables to grow food in places where in traditional soil system is not possible or cost-effective [1]. Plants in the hydroponic system can achieve 20-25\% higher yields than a soil-based system with productivity $2-5$ times higher [1].

There has been a lot of questioning whether hydroponic plants are actually more effective than plants grown in soil. An experiment study done by Maeva Makendi, showed a competitive analysis between the plant's growth in hydroponic and soil system [3]. The hypothesis stated as follows "If the hydroponic plants and plants grown in soil are given the same germinating and growing conditions, then the hydroponic plants will do as well if not even better than the plants grown in soil" [3]. The experiment was done on different kind of plants for one month. Hydroponic plants did germinate and grew faster than soil plants [3]. A study by Samangooei and others compared two of main food production method, soil-less and soil-based systems, the result of the productivity gave a similar result to Makendi study [3], [4]. According to Sardare, crops grown in soil-less culture are healthier and consistently reliable than crops grown in soil [5].

Although many studies have proven that hydroponics takes the advantages over the regular soil farming, their still some limitations to using this system. In fact, the hydroponic system requires having skills good knowledge of its principles to maintain the production [6]. Furthermore, and because this system depends on electricity, power outages can cause damage to the planted crops [7]. Also, with regards to the cost, hydroponics required much more overheads costs compared with soil traditional farming regardless its savings in the long run [7], [8].

Much more to consider, some experiments have proven that there is no significant difference between hydroponically and soil-grown crops. In fact, this experiment has been conducted by [7] to measure the quantity of the ascorbic acid $\alpha$ tocopherol in hydroponically and soil-grown raspberries. They conclude that different types of crops result in different outcomes. To make things clearer, these differences in researchers' results are due to the multiple numbers of variables to take in consideration during the hydroponic growing.

\section{Materials and Methodology}

The first step of conducting this experiment is to choose the plants type. The selected plants are vegetables, and they are cucumber and Armenian cucumber. These were chosen because they germinate quickly to expedite the experiment. A total of eight seeds will be used for this experiment, four cucumber seeds and four Armenian cucumber seeds.

The materials needed for creating the hydroponic system are the following:

1. Big plastic containers, (yogurt containers are used for recycling reason) included water with a big hole for the small plastic container to fix it in the middle of the big container.

2. Small plastic container with small holes that allows water enter inside it.

3. Small hydro stones to hold the plant.

4. Nutrient solution A, which consist of calcium and iron chelate.

5. Air pump device, which contains air hose end by an air stone.

6. Nutrient solution $B$, which consist of magnesium sulfate, potassium, copper sulfide, zinc sulfide and manganese sulfide.

7. Water.

For the traditional soil planting the following materials are used:

- Plastic container with small holes at the bottom.

- Planting soil.

- A and B nutrient solutions, as the one used for hydroponic system. 
- Water for irrigation.

For both systems, a meter was used to measure the length of the plant and $\mathrm{pH}$ meter was used to measure the $\mathrm{pH}$ degree. After conducting the experiment, the results of the two systems will be analyzed and compared using statistical experimental design approach. The analysis of variance (ANOVA) test will be conducted to test the hypothesis, whether the hydroponic system is better than the traditional system or not. The experiment levels and the variables will be identified and then analyzed by Design-Expert statistical software to test the hypothesis. Test hypothesis, variables and factors will be defined in the next section of the paper.

\section{The Experiment}

The study will focus on comparing the growth of plants grown in soil and hydroponic system given the same seed type and growing condition. Thus, the hypothesis will be:

$H_{0}$ : Seed type, planting system, and their interaction do not have significant effect on the height of the plant

$H_{1}$ : Seed type, planting system, and their interaction have significant effect on the height of the plant

\subsection{Variables}

Table 1 represents all variables in the experiment and divides them into three types: independent, dependent and controlled variables.

Table 1: The list of all the variables.

\begin{tabular}{|c|c|c|}
\hline Independent variables & Dependent variables & Controlled variables \\
\hline $\begin{array}{ll}\text { - } & \text { Types of seeds } \\
\text { Planting system }\end{array}$ & $\begin{array}{l}\text { - } \quad \text { Height of the plant } \\
\text { - } \quad \text { Length of leaves }\end{array}$ & $\begin{array}{l}\text { - } \text { Location: rooftop of building } \\
\text { - } \text { Vitamins } \\
\text { - } \\
\text { - } \text { Solutions A and B } \\
\text { - } \text { pH number }\end{array}$ \\
\hline
\end{tabular}

\subsection{Procedures}

The procedure of planting in soil system, summarized by the following steps:

1.Fill about $3 / 4$ of the plastic container with planting soil.

2.Place seeds about $1 \mathrm{~cm}$ inside the soil.

3. Add A and B nutrient solutions to the water. Then, carefully irrigate the soil with it. Check soil moisture and add $100 \mathrm{ml}$ of water every 3 days.

On the other hand, the procedure of hydroponic system, summarized by the following steps:

1.Prepare the hydroponic solution by adding $\mathrm{A}$ and $\mathrm{B}$ nutrient solutions in the water with a $\mathrm{Ph}$ of 5.5-6.5.

2.Connect the air pump device with electricity and put its air stone inside the container. Make sure that the hose is clear and transfer appropriate amount of air.

3.Plant small seedlings out of their pots and carefully washing away most of the soil from the roots.

4.Place the clean seedlings in the growing medium which contain small hydro stones and into the hydroponic solution container. See Figure 1.

5.Control the chemical balance of nutrients (solution A and B) to water by adding mostly water.

Finally, check and monitor daily plants growth for both systems in the experiment for 30 days and keep them away from pests and root-rot (if roots go slimy, the plant will turn brown and die) 


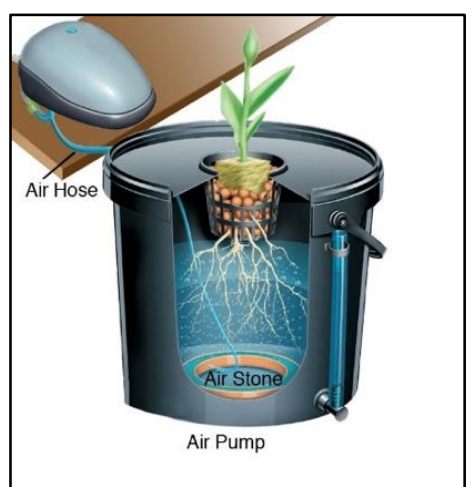

Fig. 1: The hydroponic system design.

\subsection{Data Collection}

Seed type factor has two levels and the planting system has two levels. Also, there are 2 pots for each treatment combination (see Figures from 2-5). In fact, this is a factorial experiment consist of two-factors (planting system and seed type) in two levels with replication. The list of the treatments in the experiment is shown in Table 2.

Table 2: The list of treatments with its description.

\begin{tabular}{|l|l|}
\hline Symbol & Description \\
\hline $\mathrm{S}(1,1)$ & Cucumber seed in soil planting system. No.1 \\
\hline $\mathrm{S}(1,2)$ & Cucumber seed in soil planting system. No.2 \\
\hline $\mathrm{H}(1,1)$ & Cucumber seed in hydroponic planting system. No.1 \\
\hline $\mathrm{H}(1,2)$ & Cucumber seed in hydroponic planting system. No.2 \\
\hline $\mathrm{S}(2,1)$ & Armenian cucumber seed in soil planting system. No.1 \\
\hline $\mathrm{S}(2,2)$ & Armenian cucumber seed in soil planting system. No.2 \\
\hline $\mathrm{H}(2,1)$ & Armenian cucumber seed in hydroponic planting system. No.1 \\
\hline $\mathrm{H}(2,2)$ & Armenian cucumber seed in hydroponic planting system. No.2 \\
\hline
\end{tabular}

Table 3: Heights of treatments after 30 days.

\begin{tabular}{|l|l|l|l|l|c|}
\hline \multicolumn{2}{|c|}{ Height $(\mathrm{mm})$} & \multicolumn{3}{|c|}{ Seed Type (A) } \\
\cline { 3 - 6 } & \multicolumn{3}{|c|}{ Cucumber } & \multicolumn{2}{l|}{ Armenian Cucumber } \\
\hline Planting & Soil & 94 & 105 & 93 & 78 \\
\cline { 2 - 6 } System $(B)$ & Hydroponic & 190 & 146 & 177 & 150 \\
\hline
\end{tabular}

Table 4: Lengths of leaves of treatments after 30 days.

\begin{tabular}{|l|l|l|l|l|c|}
\hline \multirow{2}{*}{ Length of Leaves $(\mathrm{mm})$} & \multicolumn{3}{|c|}{ Seed Type (A) } \\
\cline { 3 - 6 } & \multicolumn{2}{|c|}{ Cucumber } & \multicolumn{3}{c|}{ Armenian Cucumber } \\
\hline $\begin{array}{l}\text { Planting System } \\
(B)\end{array}$ & Soil & 65 & 51 & 60 & 43 \\
\cline { 2 - 6 } & Hydroponic & 50 & 76 & 69 & 57 \\
\hline
\end{tabular}




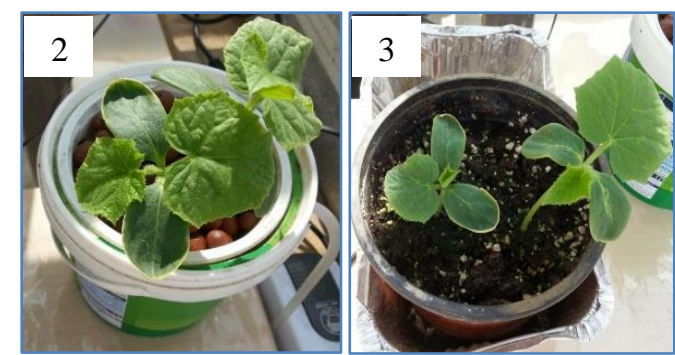

Fig. 2 and 3: Treatment $\mathrm{H}(1,1)$ in hydroponic system and treatment $\mathrm{S}(1,1)$ in soil system after 10 days.

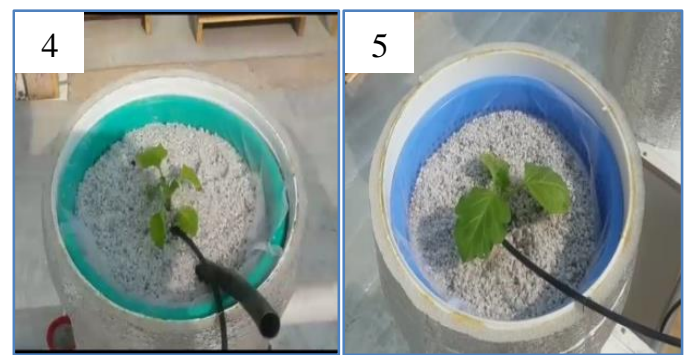

Fig. 4 and 5: Treatment $\mathrm{H}(2,1)$ during growth stages, after 7 days, after 10 days.

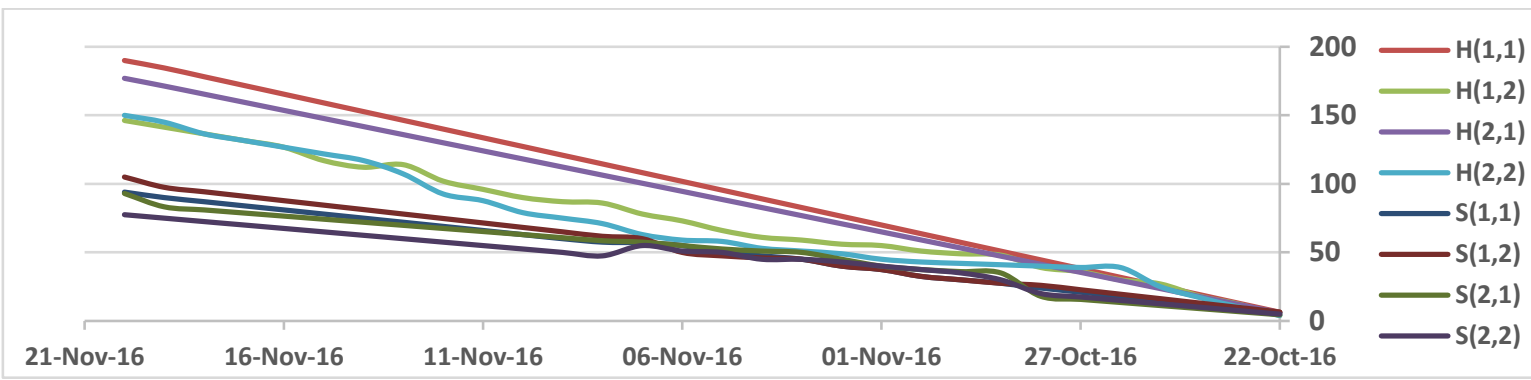

Fig. 6: Plants Height Growth in (mm) for 30 days.

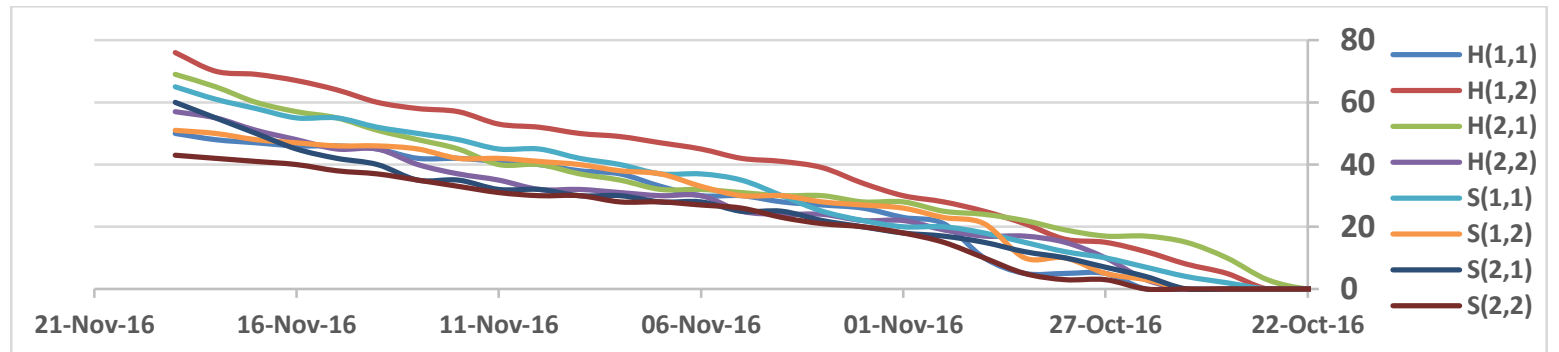

Fig. 7: Plants Leaves Growth in (mm) for 30 days.

\subsection{Statistical Analysis}

The aim of the experiment is to measure the effect of different combinations of levels of planting system and seed type on the plant height growth and leave lengths. The statistical approach analysis of variance (ANOVA) allows us to test the null hypothesis that seed type, planting system, and their interaction do not have a significant effect on the plant height and leaves [3]. Figures 6 and 7 show the increasing trend in the plant heights and growths for 30 days.

As the experiment include replications, the responses are available from two subjects at each combination of levels of planting system and seed type. So, the attendance of interaction can be measured. The test represents if that difference makes sense or it must be ignored. By analyzing the collected data from Table 3 and Table 4, three questions must be answered:

- Is there a significant difference between seed type, planting system and the interaction on plant heights and leave lengths? 
- How much is the difference between the traditional planting system and the hydroponic planting system?

- Did hydroponic system give the best growth results with all seeds types?

\section{Results}

The Model F-value of 9.70 implies the model is significant. There is only a $2.63 \%$ chance that a "Model F-Value" this large could occur due to noise. Values of "Prob > F" less than 0.0500 indicate model terms are significant. In this case, B (the planting type factor) is the significant model term. Values greater than 0.1000 indicate the model terms are not significant which include both $\mathrm{A}$ and $\mathrm{AB}$ (the type of seed factor and the interaction between two factor). See Figure 8 from DesignExpert which represent height response.

\begin{tabular}{|lrrrrrrr|}
\hline \multicolumn{1}{l}{} & \multicolumn{1}{c}{$\begin{array}{c}\text { Sum of } \\
\text { Source }\end{array}$} & Squares & DF & $\begin{array}{r}\text { Mean } \\
\text { Square }\end{array}$ & Value & Prob $>$ F & \\
Model & & 10947.38 & 3 & 3649.13 & 9.70 & 0.0263 & significant \\
& $A$ & 171.13 & 1 & 171.13 & 0.45 & 0.5371 & \\
& $B$ & 10731.12 & 1 & 10731.12 & 28.51 & 0.0059 \\
& $A B$ & 45.13 & 1 & 45.13 & 0.12 & 0.7466 \\
Pure Error & 1505.50 & 4 & 376.37 & & \\
Cor Total & 12452.88 & 7 & & & & \\
\hline
\end{tabular}

Fig. 8: ANOVA results from Design-Expert for height response.

The "Model F-value" of 0.36 implies the model is not significant relative to the noise. There is a $78.34 \%$ chance that a "Model F-value" is large could occur due to noise. In this case, there are no significant model terms. All values (A, B and the interaction $\mathrm{AB}$ ) greater than 0.1000 indicate the model terms are not significant. See Figure 9 from Design-Expert which represent length of leaves response.

\begin{tabular}{|lrrrrrr|}
\hline Source & $\begin{array}{r}\text { Sum of } \\
\text { Squares }\end{array}$ & DF & $\begin{array}{r}\text { Mean } \\
\text { Square }\end{array}$ & $\begin{array}{r}\text { F } \\
\text { Value }\end{array}$ & Prob $>$ F \\
Model & & 178.38 & 3 & 59.46 & 0.36 & 0.7834 not significant \\
& $A$ & 21.12 & 1 & 21.12 & 0.13 & 0.7371 \\
& $B$ & 136.13 & 1 & 136.13 & 0.83 & 0.4127 \\
& $A B$ & 21.12 & 1 & 21.12 & 0.13 & 0.7371 \\
Pure Error & & 652.50 & 4 & 163.13 & & \\
Cor Total & 830.88 & 7 & & & \\
\hline
\end{tabular}

Fig. 9: ANOVA results from Design-Expert for length of leaves response.

\section{Discussion}

The whole experiment took one and a half month to complete. The growth of the plants was measured for thirty days starting 22 October 2016 till 20 November 2016. The height of the plants and the length of the leaves were measured to indicate any difference in growth. The data shows treatments that are planted using hydroponic system did indeed grow faster than traditional soil system.

According to the results from Design-Expert software, the planting system did have a significant effect on the height of treatments. On the other hand, it will not affect the length of leaves. The other terms, seed type and their interaction between the planting system and seed type, did not affect the growth- height, and length of leaves of the treatments.

After the plants were germinated, the difference in the speed of growth was noticeable in the height of the treatments. For example, cucumber treatments equal $94 \mathrm{~mm}$ in soil and $190 \mathrm{~mm}$ in hydroponic. Similarly, for Armenian cucumber treatments equal $78 \mathrm{~mm}$ in soil and $177 \mathrm{~mm}$ in hydroponic. As for the length of the leaves, the differences were little. For instance, cucumber treatments equal $50 \mathrm{~mm}$ in soil and $76 \mathrm{~mm}$ in hydroponic. Similarly, for Armenian cucumber treatments equal $43 \mathrm{~mm}$ in soil and $69 \mathrm{~mm}$ in hydroponic.

All plants in the hydroponic and soil systems germinated and grew. However, since only eight treatments were studied the chance of plants not germinated is lower. If more treatments were considered the chance of plants not germinated is higher. There could also be a probability for plants to die in the middle of the experiment, especially in the soil system due 
to human factors such as overwatering. The hypothesis of the experiment is accepted for changing the planting system will influence the plants' height. In this case, the hydroponic system has a better effect as it makes the plant grow faster.

\section{Conclusion}

High demand for food production is increasing as the world population is growing. Meanwhile, the traditional farming using soil system will not cover the world's growing demand for food. Thus, developing a new farming and planting system techniques is required to avoid food crisis issue in the future. This study aimed to examine an efficient technique for alternative planting system which is the hydroponic system. The statistical experimental design approach was used to analyze and compare between traditional soil system and hydroponic system by planting two types of seeds: cucumber and Armenian cucumber in both systems.

The analysis of variance (ANOVA) is used to test two factor factorial design with two levels hypothesis, whether the hydroponic system is better than the traditional system. The final results from Design Expert software show that hydroponic planting system has a better effect than traditional soil system as it makes plants heights grow faster. On the other hand, the planting system has no significate effect on the length of leaves. Moreover, seed type and the interaction between seed type and the planting system have no signification effect on plant growth.

For future work, the experiment can be done on a larger scale, this will help in reflecting whether the hydroponic system will meet the demand of today and future market. Considering different factors such as soil type and solution type will help in implanting the experiment on a larger scale. Also, the period of the experiment should be extended as new changes may appear after a while. An important note to consider is the type of plants. In this experiment, only two plants were considered. However, the experiment can be done with different types of seeds to see if the results can be generalized to more plants.

\section{References}

[1] U. Nation, "World population projected to reach 9.8 billion in 2050, and 11.2 billion in 2100," United Nation, 21 June 2017. [Online]. Available: https://www.un.org/development/desa/en/news/population/world-population-prospects2017.html

[2] E. Okemwa, "Effectiveness of Aquaponic and Hydroponic Gardening to Traditional Gardening," International Journal of Scientific Research and Innovative Technology, vol. 2, no. 2313-3759, p. 35, 2015.

[3] D. C. Montgomery, Design and Analysis of Experiment, 8th ed. John Wiley \& Sons, Inc, 2013.

[4] C. Somerville, M. Cohen, E. Pantanella, A. Stankus and A. Lovatelli, "Small-scale aquaponic food production," 2014.

[5] M. M. S. G, "Comparative Analysis of Two Plant Growth Mediums: Hydroponic vs. Soil," The Academy of Science, Research and Medicine, 2014.

[6] M. Samangooei, P. SaSSi and A. Iack, "Soil-less systems vs. soil-based systems for cultivating edible plants on buildings in relation to the contribution towards sustainable cities," Future of Food: Journal on Food, Agriculture and Society, vol. 4, no. 2, pp. 24-39, 2016.

[7] M. Sardare and S. Admane, "A Review on Plant without Soil -Hydroponics," International Journal of Research in Engineering and Technology, vol. 2, no. 3, pp. 299-304, 2013.

[8] R. Pandey, V. Jain and K. P. Singh, "Hydroponics Agriculture: Its Status, Scope and Limitations," in Division of Plant Physiology, Indian Agricultural Research Institute, New Delhi, 2009.

[9] C. Treftz, Comparison of Nutritional and Sensory Qualities between Hydroponic and Soil-Grown Strawberries and Raspberries. Reno: ProQuest LLC, 2015.

[10] C. Treftz and S. T. Omaye, "Nutrient Analysis of Soil and Soilless Strawberries and Raspberries Grown in a Greenhouse," Food and Nutrition Sciences, vol. 6, no. 9, pp. 805-815, 2015. 